\title{
Type 1 (insulin-dependent) diabetes mellitus diagnosed during pregnancy: a clinical and prognostic study
}

\author{
K. Buschard ${ }^{1}$, P.Hougaard ${ }^{2}$, L. Mølsted-Pedersen ${ }^{1}$ and C. Kühl ${ }^{1}$ \\ I Diabetes Centre, Department of Obstetrics and Gynaecology, Rigshospitalet, University of Copenhagen, Copenhagen, and \\ ${ }^{2}$ Novo Research Institute, Bagsvard, Denmark
}

\begin{abstract}
Summary. The study concerns the clinical outcome and later prognosis (regarding permanent insulin treatment) of patients who develop insulin-dependent diabetes mellitus during pregnancy (which is different from gestational diabetes). Sixty-three such patients ( $27 \pm 1$ (SEM) years old) were delivered at the Copenhagen Centre for Diabetes and Pregnancy during the years 1966-1980. Obstetric complications such as toxaemia were seen in $9.5 \%$ of these study patients and the perinatal mortality was $6.3 \%$, both percentages being higher than in the general population $\left(1.1 \%, p<10^{-7}\right.$ and $1.0 \%, p<10^{-3}$, respectively), but similar to those observed in patients with Type 1 diabetes diagnosed before pregnancy. In contrast, the frequency of malformations was $1.6 \%$, the same as in the general population (1.4\%), but lower than that seen
\end{abstract}

in patients with long-standing diabetes $(8.3 \%, p<0.05)$. At follow-up examination $8 \pm 1$ years after diagnosis all patients were diabetic; $77 \%$ were insulin treated, having no or virtually no residual B-cell function, and were clearly Type 1 diabetic patients. After delivery $80 \%$ of the patients had a remission period (median 256 days) without insulin treatment. This remission period was absent or shortest in patients with the following characteristics ( $p \leq 0.03$ ): low age, first parity, not overweight, and high blood glucose level at diagnosis. These prognostic parameters should be considered in obligatory, clinical follow-up plans for such patients.

Key words: Type 1 (insulin-dependent) diabetes mellitus, pregnancy, prognostic parameters.
Insulin-dependent diabetes mellitus with onset during pregnancy is a disease different from the much more common gestational diabetes which reflects glucose intolerance only and does not require insulin treatment [1]. In the present study, the clinical course of the disease and the progress in the patients' diabetes after the delivery is studied. It turned out that many of the patients had a remission period during which they temporarily stopped insulin treatment, but all were diabetic at a follow-up examination $8 \pm 1$ years after delivery and the majority displayed Type 1 diabetes mellitus. The study considers factors which influence the need for constant insulin treatment - factors which may be of prognostic significance and which therefore could help in the planning of adequate control.

The fact that the study patients had no history of diabetes and probably were clinically healthy at the time of conception, but became diabetic at some stage during pregnancy, is an interesting basis for comparison with healthy non-diabetic pregnant women and with long-term (pre-conception) Type 1 diabetic patients, in order to elu- cidate clinical abnormalities connected with diabetic pregnancy.

\section{Subjects, materials and methods}

\section{Patients}

We studied all 63 patients with onset of insulin-dependent diabetes during pregnancy in eastern Denmark seen at the University Hospital from 1966-1980. The basis for the diagnosis was the classical: (1) subjective symptoms of hyperglycaemia, and (2) fasting blood glucose $>8 \mathrm{mmol} / \mathrm{l}$ or non-fasting value of $>14 \mathrm{mmol} / \mathrm{l}$. During the period of this study the procedure of the Center was to start insulin treatment only in those pregnant women who developed clear-cut insulin-dependent diabetes whereas women with impaired glucose tolerance received only dietary treatment. There was no change in the number of patients or in the concept of treatment during the 15-year study period. Incidence results based on these patients have been published earlier [2]. Data from the time of diagnosis was extracted from the hospital records. The distribution of diagnosis by trimester was as follows: 1 st: $13 \%, 2 \mathrm{nd}: 17 \%$, and $3 \mathrm{rd}: 70 \%$. Of the patients $24 \%$ were more than $10 \%$ overweight [3] when they con- 
ceived. At diagnosis the mean fasting blood glucose level of the patients was $15.6 \pm 1.3 \mathrm{mmol} / 1$ and $81 \%$ had ketonuria. Maximal insulin dose during pregnancy was $49 \pm 3 \mathrm{IU} / 24 \mathrm{~h}(0.80 \pm 0.05 \mathrm{IU}$. $24 \mathrm{~h}^{-1} \cdot \mathrm{kg}^{-1}$ bodyweight).

At the follow-up, in which 60 of the patients participated, 46 patients were currently insulin treated, nine of these without interruption from the time of onset of disease during pregnancy. Thirty-seven had stopped taking insulin during the remission period for 256 days (median value), beginning from nine days (median value) after delivery. Fourteen patients were not insulin treated at follow-up, but of the 11 examined all displayed abnormal carbohydrate tolerance, seven with fasting blood glucose values above $14 \mathrm{mmol} / \mathrm{l}$, and four with markedly pathological glucose tolerance tests. These non-insulin treated patients were seen 1,640 days after delivery (range $1,157-4,667$ days), while the time between the delivery and followup in the insulin treated patients was 2,898 days (range 578-5,870 days).

At follow-up, patients treated with insulin displayed an average stimulated plasma C-peptide value of $0.12 \pm 0.02 \mathrm{nmol} / \mathrm{l}$, none were above $0.60 \mathrm{nmol} / \mathrm{l}$; the majority $(59 \%)$ less than $0.05 \mathrm{nmol} / 1$, which indicates total absence of B-cell function. Three of the non-insulin treated patients displayed stimulated C-peptide values below or just around $0.60 \mathrm{nmol} / \mathrm{l}$, which has been considered to be the limit below which insulin should be given [4].

The tissue type distribution of the patients was in accordance with that of non-pregnant diagnosed Type 1 diabetic patients [5] - a high proportion of HLA-DR 3 and/or DR $4(92 \%)$, which is markedly different from the distribution in a control group from the general population $\left(57 \%, p<10^{-4}\right)$.

Toxaemia was defined as the presence of two of the following three symptoms: (1) blood pressure $>140 / 90 \mathrm{~mm} \mathrm{Hg}$ on two occasions, (2) >100 mg proteinuria during a $24-\mathrm{h}$ period on two occasions, and (3) significant oedema of face and fingers. Approximately $10 \%$ of the patients suffered from more severe symptoms (blood pressure $>180 / 100 \mathrm{~mm} \mathrm{Hg},>1 \mathrm{~g} / 24 \mathrm{~h}$ proteinuria and/or monstrous oedema. Hydramnios was defined as more than 1.51 of amniotic fluid in the last trimester.

\section{Comparison between groups of patients and healthy control subjects}

The study group with insulin-dependent diabetes developed during pregnancy (named the "New White B patients") are compared with other types of pregnant diabetic patients and healthy pregnant women. An "Old White B group" comprises 133 patients with Type 1 diabetes of less than 10 years' duration diagnosed before pregnancy. These patients were delivered at the University Hospital's Diabetes Centre over the same period as the "New White B patients", i.e. 1966-1980. Some of the clinical data, however, stems only from the years 1966-1968 and 1975-1980. A "White C-F patient group" of 318 patients - longstanding ( $>10$ years) Type 1 diabetes before pregnancy - also derives from the years 1966-1980-some data only from 1966-1968 and 1978-1980. The control group of 59,773 individuals comprises all Danish women delivered in 1979 , the only year within the study period for which statistical data was available [6].

\section{Statistical analysis}

Data is expressed as means \pm SEM, or as medians. The proportion of women not insulin treated was found by the Kaplan-Meier estimator, using time since delivery until start of insulin treatment. The nine patients constantly insulin treated were counted as response times of 0 . The time from giving birth until cessation of insulin treatment (median nine days) is included in the response time. Subgroups were compared by means of the log rank test, Kalbfleisch and Prentice [7], using a significance Ievel of 0.05. All $p$-values are two-sided. Tests in
Table 1. Clinical obstetric data. The mentioned $p$-values refer to differences between the group of New White B patients and the other groups

\begin{tabular}{|c|c|c|c|c|}
\hline & $\begin{array}{l}\text { New } \\
\text { white B }\end{array}$ & $\begin{array}{l}\text { Old } \\
\text { white B }\end{array}$ & $\begin{array}{l}\text { White } \\
\text { C-F }\end{array}$ & $\begin{array}{l}\text { General } \\
\text { population }\end{array}$ \\
\hline Age (years) & $26.9 \pm 0.7$ & 27.8 & 25.2 & 26.4 \\
\hline Parity (no.) & $2.0 \pm 0.2$ & 1.8 & 1.6 & - \\
\hline Toxaemia (\%) & 9.5 & 8.2 & 15.2 & $1.1\left(p<10^{-7}\right)$ \\
\hline Hydramnios (\%) & 12.7 & 9.6 & $\begin{array}{l}31.7 \\
(p<0.03)\end{array}$ & $0.4\left(p<10^{-9}\right)$ \\
\hline Abruptio (\%) & 3.2 & 1.4 & 0.9 & 0.8 \\
\hline $\begin{array}{l}\text { Week of birth } \\
\text { (week no.) }\end{array}$ & $36.7 \pm 0.2$ & 36.7 & 36.3 & 39.7 \\
\hline Sectio $(\%)$ & 30.2 & 50.7 & $\begin{array}{l}65.7 \\
(p<0.01)\end{array}$ & $10.3\left(p<10^{-5}\right)$ \\
\hline Birth weight $(\mathrm{g})$ & $3332 \pm 88$ & 3455 & 3278 & 3400 \\
\hline $\begin{array}{l}\text { Birth weight } \\
\text { under } 2,500 \mathrm{~g}(\%)\end{array}$ & 10.9 & 6.0 & 14.8 & 5.4 \\
\hline $\begin{array}{l}\text { Birth weight } \\
\text { over } 4,000 \mathrm{~g}(\%)\end{array}$ & 18.8 & 22.9 & 15.7 & 13.1 \\
\hline Birth length $(\mathrm{cm})$ & $50.4 \pm 0.4$ & 50.6 & 49.8 & - \\
\hline $\begin{array}{l}\text { Perinatal } \\
\text { mortality }(\%)\end{array}$ & 6.3 & 4.5 & 9.5 & $1.0\left(p<10^{-3}\right)$ \\
\hline $\begin{array}{l}\text { Malformations, } \\
\text { major (\%) }\end{array}$ & 0.0 & $\begin{array}{l}8.3 \\
(p<0.05)\end{array}$ & $\begin{array}{l}8.7 \\
(p<0.05)\end{array}$ & 1.4 \\
\hline $\begin{array}{l}\text { Malformations, } \\
\text { minor }(\%)\end{array}$ & 1.6 & 0.0 & 1.8 & \\
\hline $\begin{array}{l}\text { Sex distribution } \\
\text { (\% males) }\end{array}$ & 56.3 & 53.4 & 47.8 & 51.4 \\
\hline
\end{tabular}

Table 1 are $X^{2}$-tests in the corresponding two by two tables. For malformations Fisher's exact $p$ is calculated, because of the small numbers.

\section{Results}

Clinical obstetric parameters are recorded in Table 1. The mean age at delivery for the New White B patients was similar to that of the Old White B patients, the White $\mathrm{C}-\mathrm{F}$ patients, and the control subjects. Concerning the birth numbers, possibly the New White B group had higher parity, but data for the other groups was insufficient for precise analysis.

Regarding obstetric complications such as toxaemia and hydramnios, these occurred with similar frequencies in the New White B group and in the Old White B group all percentages being much higher than in the control group $\left(p<10^{-7}\right)$.

Time of delivery of the patients was typically three weeks before term, dictated by the Centre's general rule for induction of labour in diabetic patients. Caesarian section was undertaken three times as frequently in the New White B patients as in the control group $\left(p<10^{-5}\right)$. In Old White B and White C-F groups, Caesarian section was of similar or higher incidence as in the New White B group. The newborn in all groups were of similar mean weight and length. 

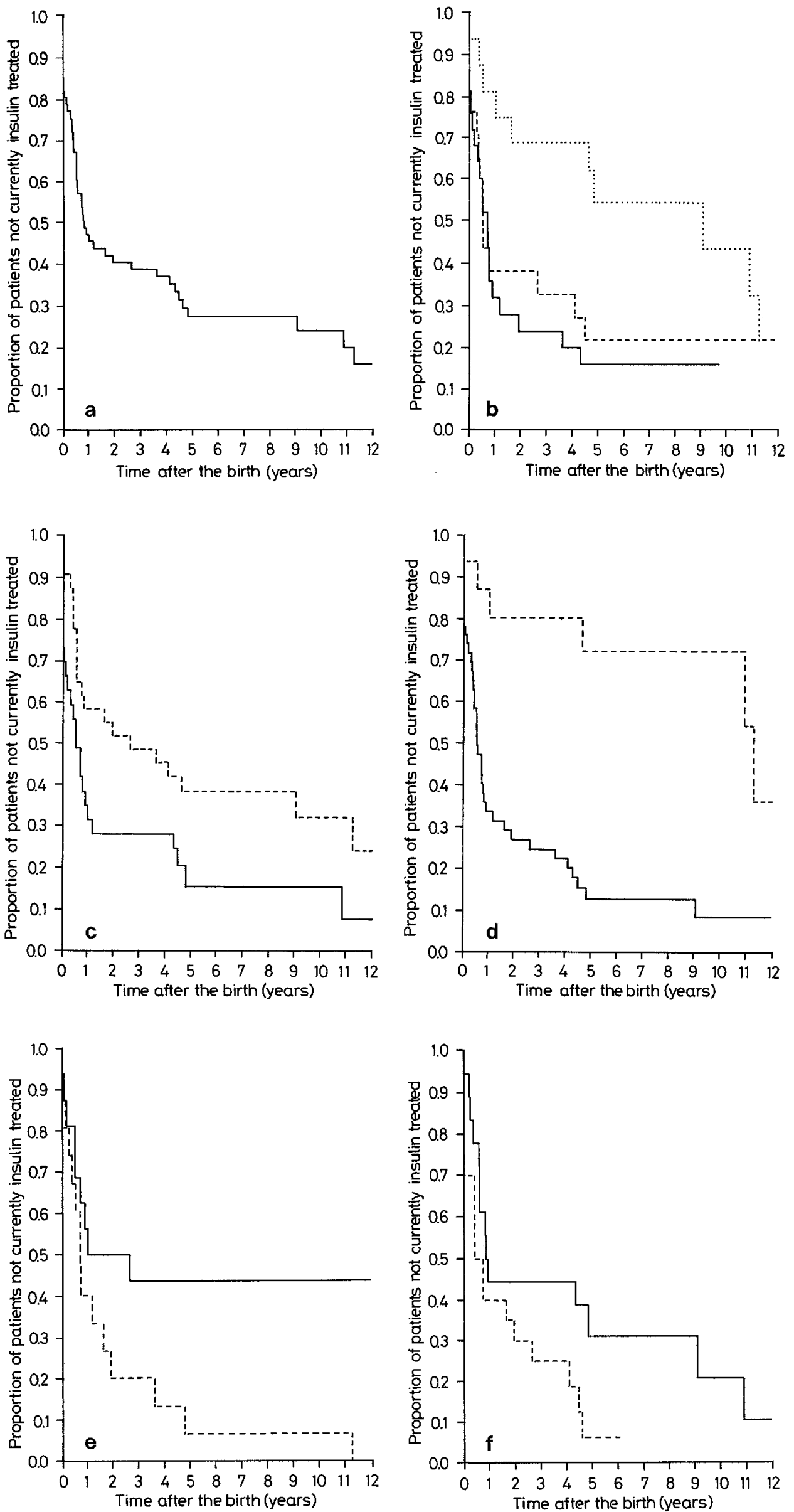

Fig. 1 a-f. Diagrams indicating the proportion of patients having insulin treatment as a function of time after delivery (years). a shows the patients as an entire group $(n=63)$. b shows the patients in different age groups: $\leq 24$ years (full line, $n=25$ ), $25-29$ years (broken line, $n=22$ ), and $\geq 30$ years (dotted line, $n=16$ ). There was a significant difference between the groups $(p=0.03)$. c shows the patients in groups of prima (full line, $n=30$ ) and multi (broken line, $n=33$ ) para $(p=0.03)$. d shows the patients in groups of normal weight $(<10 \%$ overweight, full line, $n=47)$ and overweight ( $\geq 10 \%$ overweight, broken line, $n=16)(p=0.03)$. e shows the patients in groups with low $(<15.0 \mathrm{mmol} / \mathrm{l}$, full line, $n=16)$ and high ( $\geq 15.0 \mathrm{mmol} / 1$, broken line, $n=16$ ) blood glucose values at diagnosis $(p=0.03)$. f shows the patients in groups with (full line, $n=18$ ) and without (broken line, $n=20$ ) HLA-DR 3. There was no significant difference between the groups $(p=0.07)$ 
Perinatal mortality in the New White B group was much higher than in the control group $\left(p<10^{-3}\right)$ and similar to that in the other diabetic groups. Regarding the exact causes of perinatal mortality in the New White B group, three children died intrauterinely due to severe ketoacidosis and one at birth of an acidosis which could not be corrected.

Congenital malformations were of the same frequency in the New White B group as in the control group, in divergence to the other diabetic groups where malformation incidence was significantly higher $(p<0.05)$. Minor deformities were of low and similar occurence in all groups. Of the New White B newborn $56 \%$ were male, but this proportion was not significantly different from that in the other groups.

Figure 1 a shows how many patients who were under insulin treatment, and at what times, following delivery. All patients were, as mentioned, clearly diabetic at the time of follow-up, but many had had a remission period of shorter or longer duration during which insulin was not given. The data was thus further analysed in order to identify potential markers of prognosis, indicating the length of a possible pause in insulin treatment after the delivery. By means of univariate analyses, low age ( $p=0.03$, Fig. 1 b), first parity $(p=0.03$, Fig. $1 \mathrm{c})$, normal weight $(p=0.0002$, Fig. $1 \mathrm{~d})$, and high blood glucose value at time of diagnosis ( $p=0.03$, Fig. 1 e) were found to indicate a poor prognosis meaning no, or only a short, remission period.

The time during pregnancy when diabetes was diagnosed (pregnancy week for start of insulin treatment), birth weight, fetal sex, and patient tissue type were without prognostic significance in determining the need for permanent insulin treatment. However, HLA-DR 3 (but not HLA-DR 4) tissue type (Fig. $1 \mathrm{f}$ ) tended to mark a worse prognosis $(p=0.07)$.

\section{Discussion}

This study describes the clinical course of Type 1 diabetes with onset during pregnancy. Comparison is made with other diabetic patients in whom diabetes preceded pregnancy, and a healthy control group. The frequency of obstetric complications among all Type 1 diabetic pregnant women was similar, but the frequency of major congenital malformations in the study group was surprisingly low, i.e. no higher than in healthy women.

Analysis of the data concerning the possible occurrence of a remission period pointed to a number of phenomena as being of prognostic significance. The young; the first para; those not overweight, and those with higher blood glucose levels at the time of diagnosis had no or only a short remission period. It must be assumed that these patients sustain more rapid and comprehensive B-cell destruction.

Because of the natural dependence between age and parity it is relevant to assess their joint influence on prognosis. This is difficult with the long-rank test be- cause of the small number of women in the subgroups. Therefore, a proportional hazards model [7] was performed, including age in years and parity number as covariates. It turned out that age was most important and that when age was included, parity did not yield significant information, although there was a tendency in the same direction as for the univariate analysis.

Very high blood glucose values and massive ketonuria are often seen at diagnosis of Type 1 diabetes during pregnancy because of a rapid and acute onset of the disease. Such emphatic metabolic derangement probably has profound effects on the course of pregnancy [1], reflected by the high perinatal mortality and the frequency of other obstetric complications. In order to prevent these complications, it seems important to centralize the treatment of newly diagnosed pregnant Type 1 diabetic patients by immediate admission to hospital centres specializing in the care of these relatively rare patients.

Of interest is the low incidence of congenital malformation in the 64 children of the New White B diabetic women - only one minor deformity - hypospadia. This incidence is as in the normal population, and significantly lower than in women who were diabetic before pregnancy. It thus seems likely that a decisive factor is the probable normoglycaemic status of the New White B diabetic patients at the time of conception and the first period thereafter. This idea derives some indirect support from the literature $[8,9]$.

At follow-up, all patients were found to be diabetic. Some had been insulin treated continuously from time of diagnosis; others had had a shorter or longer period without insulin. Among those women not insulin treated at the time of follow-up were several who in all probability should have been, and all were in need of strict dietary control. Many patients lacked insight into their condition. An important conclusion of the study is, therefore, that women with diabetes newly diagnosed in pregnancy are in need of regular control - permanently - after delivery, irrespective of an apparent lack of need of insulin treatment for a period after delivery. The study indicates that all the patients continue to have diabetes and that the majority display Type 1 diabetes mellitus.

For future patients who develop insulin-dependent diabetes during pregnancy and stop insulin treatment afterwards, the recorded prognostic factors (youth, prima para, normal weight, and high blood glucose level at diagnosis) should be considered when deciding the optimal intervals between clinical controls after delivery, as such patients remain diabetic and will very probably need insulin treatment at some time in the future. There might, also for the non-pregnant diabetic patients be a correlation between some of these factors and the extent and rapidity of B-cell destruction. Regarding youth as a prognostic factor, our observation is reinforced by other studies [10-12] in which a higher prevalence of B-cell function is seen after several years' duration of diabetes in patients diagnosed at a higher age in comparison with patients diagnosed when younger. 


\section{References}

1. Pedersen J (1967) The pregnant diabetic and her newborn. Munksgaard, Copenhagen

2. Buschard K, Buch I, Mølsted-Pedersen L, Hougaard P, Kühl C (1987) Increased incidence of true type I diabetes acquired during pregnancy. Br Med J 294: 275-279

3. Natvig H (1956) Nye høyde-vekttabeller for norske kvinner og men. Landsforeningen for kosthold og helse. Universitetsforlaget, Oslo

4. Madsbad S, Krarup T, McNair P, Christiansen C, Faber OK, Transbøl I, Binder C (1981) Practical clinical value of the C-peptide response to glucagon stimulation in the choice of treatment in diabetes mellitus. Acta Med Scand 210: 153-156

5. Møller-Jensen B, Buschard K, Buch I, Mølsted-Pedersen L, Kühl C, Jakobsen BK, Svejgaard A (1987) HLA associations in insulin-dependent diabetes mellitus diagnosed during pregnancy. Acta Endocrinol 116:387-389

6. Medicinsk Fødselsstatistik 1979. Vitalstatistik I: 1: 1982, Sundhedsstyrelsen, Copenhagen

7. Kalbfleisch JD, Prentice RL (1980) The statistical analysis of failure time data. Wiley, New York

8. Fuhrmann K, Reiher H, Semmler K, Fischer F, Fischer M, Glöckner E (1983) Prevention of congenital malformations in infants of insulin-dependent diabetic mothers. Diabetes Care 6: 219-223
9. Goldman JA, Dicker D, Feldberg D, Yeshaya A, Samuel N, Karp M (1986) Pregnancy outcome in patients with insulin-dependent diabetes mellitus with preconceptional diabetic control: a comparative study. Am J Obstet Gynecol 155: 293-297

10. Ludvigsson J, Heding LG (1976) C-peptide in children with juvenile diabetes. Diabetologia 12: 627-630

11. Madsbad S, Faber OK, Binder C, McNair P, Christiansen C, Transb $\varnothing 1$ I (1978) Prevalence of residual beta-cell function in insulin-dependent diabetics in relation to age at onset and duration of diabetes. Diabetes 27 [Suppl. 1]: 262-264

12. Hoogwerf BJ, Rich SS, Barbosa JJ (1985) Meal-stimulated Cpeptide and insulin antibodies in Type 1 diabetic subjects and their nondiabetic siblings characterized by HLA-DR antigens. Diabetes 34: 440-445

Received: 6 March 1989

and in revised form: 24 August 1989

Dr. K. Buschard

The Bartholin Institute

Kommunehospitalet

DK-1399 Copenhagen K

Denmark 